\title{
New Research on Gender in Political Psychology
}

\section{Mentoring to Fix the}

\section{Leaky Pipeline}

\author{
Angela L. Bos, College of Wooster \\ Monica C. Schneider, Miami University, Ohio
}

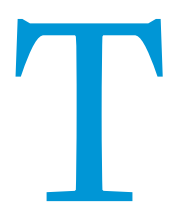

his symposium consists of three papers written after a small mentoring conference, New Research on Gender in Political Psychology, which was held in New Brunswick, New Jersey, March 4-5, 2011. ${ }^{1}$ As junior scholars, we received a grant from the National Science Foundation (\#SES-1014854) to organize a conference for the purposes of mentoring pretenure faculty and promoting scholarship on gender in political psychology. Each of the three articles in this symposium focuses on a different aspect of the conference.

In the current paper, we give an overview of the conference by describing the conference need, goals, structure, and assessment. We lay out a model for future successful mentoring conferences. Next, Erin Cassese, Angela Bos, and Lauren Duncan report on innovative teaching ideas discussed at the conference. They develop an argument for mainstreaming gender throughout the political science curriculum and share specific exercises conference participants have used successfully to this end. Finally, Rebecca Hannagan, Jill Greenlee, and Monica Schneider give an overview of the research directions and new methodologies identified in the conference.

This symposium, then, is intended to share a model for creating intentional and productive mentoring opportunities for scholars at all stages of their careers and to disseminate the results of our conference.

\section{THE NEED FOR MENTORING}

Although the prototypical mentoring relationship in academia is that between graduate student and adviser, the need for mentoring extends beyond graduate school. Junior faculty members navigate the difficult and often frustrating publishing process, promote their research to potential "outside reviewers," learn ways to be effective yet efficient in their teaching, and discern which service activities they should engage in or avoid at their new institution. Often, the institution where the newly minted $\mathrm{PhD}$ lands is quite different from his or her PhD-granting institution with unfamiliar norms, a lack of a critical mass of scholars in one's subfield, and often no formal mentoring process to assist with these challenges. The need for mentoring exists, but the discipline lacks a mechanism through which quality mentoring might occur.

On the positive side, many conferences or sections now offer some kind of mentoring program, although these programs are sometimes limited to graduate students. In addition, the American Political Science Association (APSA) has made efforts to integrate working groups and short courses into its conferences that can potentially lead to mentoring relationships. ${ }^{2}$ However, for the most part, opportunities for high-quality mentoring opportunities at large political science conferences [e.g., APSA and Midwest Political Science Association (MPSA)] are limited. The presentation format of research panels or even section-sponsored panels giving advice on professional development topics does not create meaningful one-on-one interaction. Thus, attempts to foster mentoring at large conferences rarely fill the needs we have identified.

We especially see the need for mentoring pretenure women faculty and, in particular, those scholars-men and womenwho study gender in political science. In fact, many similar recommendations regarding mentoring were made by APSA's NSF-funded Women's Advancement in Political Science Report (American Political Science Association 2005). The contributors to the report suggested the creation of "intentional networks" of scholars, particularly for junior scholars approaching tenure (the "make or break years" according to one contributor). Such networks, according to the authors, can help address the "leaky pipeline" of pretenure women as well as minorities. The creation of "intentional networks" of scholars also reflects a broader finding that mentoring networks or constellations are effective in faculty development (Sorcinelli and Yun 2007, Van Emmerick 2004, Yun and Sorcinelli 2008).

One particular area requiring better mentoring is the promotion and publication of high-quality research in the field of women in politics. Such research is underrepresented in the discipline, particularly in quality publications. For example, Kelly, Williams and Fisher (1994) state:

A survey of nearly 100 years of publications in the top 15 political science journals found only 433 articles on women and politics or feminist theory before 1990 , and almost half of these 
appeared in the 1980 os. In the first 12 years of its existence, Women $\mathcal{E}$ Politics published one-third of all women and politics articles that appeared in the top 15 journals.

In sum, a great need exists for mentoring of pretenure faculty, particularly women faculty and those studying gender and politics. This point is further supported in APSA's Task Force on Political Science in the 21st Century (2011) report that highlights the effectiveness of mentoring in putting young women and faculty of color on course for a successful career.

\section{CONFERENCE GOALS}

In light of these identified needs, our goals for the conference were as follows:

1. Provide opportunities for quality and sustained interaction to create a small, close-knit community of junior and senior scholars engaged in the area of women and politics;

2. Facilitate the creation of holistic academic mentoring relationships between scholars focusing not only on intellectual development, but also professional development related to teaching, service, research and navigating the academy, connecting scholarship to modern politics, and maintaining work-life balance;

\section{CONFERENCE STRUCTURE}

We made a number of calculated decisions on how to structure the conference to best achieve these goals. Several of these decisions are described here.

\section{Application Process}

We began by finding willing participants on both a junior and senior level. We defined junior scholars as those in their postgraduate, pretenure years. Senior scholars were considered to be posttenure. We decided that only exceptional graduate students close to entering tenure track positions would be admitted to keep the mentoring focus on the critical pretenure years.

Identifying senior scholars, who might have an interest in the conference based on their existing publication record, was fairly easy. For junior scholars, who might have less of a paper trail, we publicized widely. In particular, we issued an open call for proposals through APSA, MPSA, the Women and Politics sections within APSA, the APA's Society for the Psychology of Women Division, and the International Society for the Study of Political Psychology (ISPP) (including the listserv for junior scholars) from March through July 2010. We also publicized our efforts through the Women's Caucus for Political Science and the Midwest Women's Caucus for Political

\section{In short, we imagined that participants would continue to feel part of a close-knit academic community whose members will assist them throughout their careers.}

3. Capitalize on these mentoring relationships and the small conference structure to improve research in this field and to identify future directions for research on gender and political psychology; as part of this, our goal was that paper presenters leave with worthwhile feedback for revisions and plans to publish at a quality outlet within one year.

Given our goals, we expected participants to report that they experienced a different type of conference, one whose format better helped them meet their professional goals. We hoped that participants would agree that they gained insight into all aspects of academia life: research, teaching, and service. In particular, we wanted participants to generate new research ideas and publish women and politics research in top outlets. We anticipated that all participants would feel better equipped to face the challenges of teaching gender. For junior scholars, we hoped that over the course of the conference they would learn how to navigate service demands and develop relationships with key senior scholars. Finally, we hoped that senior scholars, who were fulfilling a service obligation, would feel as though they had made a difference in a young scholar's career.

Because of the creation of strong relationships, we hoped that after the conference all participants would keep in touch, collaborate with one another on research, share innovations regarding teaching gender, as well as read and respond to each others' work. In short, we imagined that participants would continue to feel part of a close-knit academic community whose members will assist them throughout their careers.
Science. We sent a postcard invitation to members of these organizations and to graduate programs with a strong political psychology and/or women and politics focus. Finally, we reviewed recent journals and conference programs to identify scholars to invite.

An important part of the conference publicity was the website, logo, and mailing materials. Our design team at Space 2 Burn made sure that everything-from colors to picturesreflected the smart, fresh, and inclusive mood that we wanted to convey. Professional-looking promotional materials could convey the conference goals and help us attract conference participants committed to our goals.

In addition to casting the net widely, we wanted to ensure that the conference participants were committed to helping to meet the conference's mentoring goals. Thus, to apply for the conference, all scholars had to submit a one-page participant statement focused on how they would help achieve the goals of the conference, foster collaborative and mentoring relationships with other conference participants, and benefit from this conference. In addition, applicants who wanted to propose a paper were asked to submit a three-page summary of the paper's theory, methods, and findings. We judged whether papers would be close to publication by the time of the conference.

After receiving 41 participant applications, we accepted 32 participants (20 junior, 12 senior). Among the 24 paper proposals, we selected 11 (five junior solo authors, three junior co-author combinations, two senior solo authors, and one 
junior-senior coauthor combination) to be presented. In considering applications, we kept the group small and resisted the temptation to accept too many papers for presentation because that would not leave sufficient time for discussion and reviewer feedback.

\section{Structured Mentoring Opportunities}

In every planned activity of the conference we created opportunities for mentoring between junior and senior scholars. We hoped that engineering interaction focused on a broad spectrum of topics in various formats would help achieve our goals. We fostered an environment in which participants felt comfortable speaking frankly to one another. For example, as an opening to the conference, we created a "Human Bingo" game so that participants could meet each other before jumping into more intellectual conversation (details provided in the Appendix).

Next, all participants were assigned to mentoring groups to meet at meals throughout the conference. One senior scholar in each group served as facilitator; each facilitator received a set of cards with a series of "discussion starters" that posed questions to focus the conversations. At first, the questions were introductory in nature (e.g., describe your research interests and institution). Later, the questions asked participants to discuss specific issues such as teaching (e.g., "how do the dynamics of age and gender affect the dynamics of our classrooms?") and service (e.g., "related to service: how can we be good colleagues/citizen-scholars without going crazy?"). This structure facilitated conversation around key issues in a way that was not intimidating for junior scholars and made it easy for senior scholars to provide specific advice.

We wanted to provide junior scholars with chances to gain insight into a variety of professional topics as well as the opportunity to discuss teaching and the application of research to practical politics. To this end, we asked participants, mostly senior scholars, to prepare a slate of workshops and roundtables focused on a wide variety of professional development topics. Participants could attend two of four discussions on "Navigating the Publishing Process" (publishing a book or journal articles), "Improving Your Dossier," or "Getting Funds to Conduct Your Research." We also held a roundtable on "Innovative Ways to Integrate Gender across the Curricula" and cohosted a reception and roundtable with students and professors from Rutgers' Center for American Women and Politics (CAWP) featuring campaign practitioners Kellyanne Conway, Manolo González-Estay, Celinda Lake, and activist Candy Straight, who routinely work with women in politics. The roundtable and reception facilitated a conversation between practitioners and scholars to publicize the findings from academic research about gender and political psychology. Linking practitioners and scholars also improves the quality of academic research (tying to our academic goals).

\section{Intellectual Focus}

Several aspects of the conference were structured to meet our goals of publication in top journals and identification of future research directions. First, we communicated our expectation to participants that everyone would read all papers in advance to ensure that questions and comments from the audience would be useful. Second, we kept panels small and presentations short to allow for enough time for high-quality, detailed discussion. Each paper was allowed one half hour for presentation and discussion. Third, author(s) met for one hour with two reviewers-one junior and one senior scholar - who read and created a set of comments about the work prior to the conference. Thus, all presenters received valuable feedback on their work with the encouragement to publish their work within one year. Fourth, all participants were invited to participate in a "read around" session whereby they could bring a two- to threepage research proposal to be read by other participants to get feedback "on the spot." Finally, our last group session focused on "new directions" in research. We believe that this combination of activities produced interactions that will lead to top scholarship and stimulate new research in the field.

\section{Future Impact}

Because we wanted to ensure that the impact of the conference did not end with the conference closing, we elected to have a session in which participants could think and write about their future plans as they related to teaching, research, and service. Participants found a quiet spot where, in the journal we provided, they reflected on the conference and its future. We provided a variety of different prompts-all included in the Appendix-for use by scholars at all stages (e.g., "name three people who you think you could send your research and writing to" and "name the specific paper on which you might like feedback and a reasonable date that you could send this paper"). At the closing dinner, we requested that participants discuss their individual future plans and whether or not there might be ways to engage collectively in the conference topics. Finally, we created a Facebook page for future communication and hosted a reunion dinner at the MPSA meeting. The dinner, also funded by our NSF grant, took place less than a month after the conference.

\section{ASSESSMENT}

Twenty participants completed a postconference evaluation that included a series of closed-ended items based on the conference goals and open-ended questions about what they liked best, what could be improved, and general comments. We briefly summarize their responses to illustrate participant experiences and to assess how the conference met its goals.

\section{Structured Mentoring Opportunities}

Conference participants viewed the conference as different from other conferences and as a very fulfilling experience. Ninety-five percent agreed or strongly agreed that the conference was more helpful than other conferences in helping them achieve their professional goals. Ninety percent of participants agreed or strongly agreed that the professional development experiences at the conference were ones unavailable to them at their current institutions. One participant wrote that the conference provided "networking opportunities I would not have had at my home institution, or in a standard conference." 
Participants reacted favorably to the broad range of mentoring opportunities. Ninety-five percent of participants agreed or strongly agreed that the conference met its goal to bring junior and senior scholars together in mentoring relationships. Additionally, 90\% found the mentoring group discussions helpful. One junior scholar participant stated, "The structured mentoring discussions were really terrific. Sometimes it is difficult to approach senior people and ask them questions about maintaining an active research agenda or other topics." Junior scholars felt the mentoring experience was useful. One noted that the best part of the conference was that it offered "opportunities to network with other scholars interested in similar things-for advice, mentoring, now and in the future, on both professional development and my research in an environment that made us network." Another identified the mentoring groups as the best part of the conference that helped to "demystify tenure, the grant reviewing process, and the publication process, etc." Participants especially noted that the mentoring interactions were successful because of the frankness and honesty in the discussions regarding a range of issues. As one participant noted, junior scholars had the opportunity to learn "about both the good and the bad. We often times don't realize that everyone gets rejected."

\section{Intellectual Focus}

Participants reported that our focus on research and publishing was a successful aspect of the conference. One participant noted that the best part of the conference was "meeting and tion. I also gained much from talking about my current research project even though I did not specifically present a paper."

All participant respondents agreed or strongly agreed that the conference goal regarding teaching had been met and most (95\%) felt that the conference gave them concrete ideas to use in their teaching in the area. To prompt discussions of particular teaching activities related to gender, we gave every participant a copy of Traister's (2010) Big Girls Don't Cry: The Election that Changed Everything for American Women, donated by the publisher, Simon and Schuster. Based on their experiences with the teaching panel and the ideas generated at the conference, at least five participants plan to incorporate the book in their classes over the next academic year. Furthermore, $85 \%$ of participants agreed that the conference met its goal to connect academics studying gender and political psychology with campaign professionals.

\section{Future Impact}

In terms of creating a strong community and networks between scholars, $100 \%$ of respondents agreed that they had met scholars to whom they could send their work for suggestions. One participant's comments illustrate the community that was built: "Spending two days with folks helped facilitate organic networking opportunities that I would not (and have not) pursued in other shorter interactions. I met people with whom I can share my work. It was just nice to deepen personal connections with people which will make it easier

\section{As one participant noted, junior scholars had the opportunity to learn "about both the good and the bad. We often times don't realize that everyone gets rejected."}

discussing research with senior scholars" and another "advice on journal publishing and grant proposals." Only one participant (5\%) felt that s/he did not gain confidence with regard to navigating the publishing process. Yet, many participants were not ready to state that the conference met its goal to publish women and politics work in top outlets. Sixty percent felt that the conference had met this goal, $20 \%$ chose the middle option, and $20 \%$ disagreed. Comments in the margin indicated that it was too early to tell. We plan to revisit our publication goal one year post-conference with a second follow-up survey to get valid data on the effect of the conference on publishing.

The structural decisions of including paper presentations and having time for individual feedback were reported to be successful. Several scholars stated that the paper presentations were one of the best parts of the conference. One stated that the conference generally "raised awareness of emerging gender politics work." Numerous paper presenters noted that the reviewer feedback was crucial to improving their work. One noted: "I loved the individual feedback session for research-it was so much more helpful than any panel feedback I've ever received at a conference." Even one of those who did not present still appreciated that "the article publishing panels were content rich and had great practical applica- for me to contact them in the future about work (and also, I feel like I have some new friends)." Another encouraging comment, in response to what was best about the conference, was: "The opportunity to meet this amazing group of people was worth attending. I have been inspired to improve my current projects, have thought of new projects, learned what others are working on, plan to meet up at conferences in the future to workshop ideas, and have importantly found my peers. Peers are not just those working in my area but also those willing to share feedback."

There are several other indicators of the conference's success in creating intentional networks. Thirteen participants met for a reunion dinner at the 2011 MPSA meeting and a dozen have committed to meeting at the 2012 MPSA. Furthermore, our Facebook page has 25 members and is used often: Participants have posted congratulations to other participants when they have won awards or published papers. Discussions about books for courses next year and invitations to submit conference papers have been posted. Of course it is common to "like" your friends' status updates; we have observed that our conference peers not only "like" but also supportively comment on a range of professional development status updates. 
Finally, it was important to us that the senior scholars feel rewarded for their amazing contributions to mentoring their junior colleagues in the field. All eight senior scholars completing the evaluation strongly agreed that they "felt that they had made a difference in a career of a junior scholar."

We asked participants to speculate how the conference would influence them in the future. Ninety-five percent stated that they would participate in a mentoring conference like this in the future. In addition, $70 \%$ agreed that they would collaborate with fellow participants in the future $(30 \%$ chose the middle option, neither agreeing nor disagreeing). All participants stated that they would keep in touch with other participants in the future. Finally, 95\% felt as though this type of conference has great potential to help fix the "leaky pipeline."

\section{Areas for Improvement}

Overall, participants reacted very favorably to their mentoring group experiences, but some wondered if the groups could change over the course of the conference. This would certainly be a suggestion to consider. On the one hand, we wanted people to have lots of exposure to many different people; on the other hand, we wanted to make sure that mentors and mentees really got to know each other. skipped panels if it had been more convenient for them to do so.

\section{CONCLUSION}

All told, our conference was successful in meeting our goals. One of the senior scholar participants told us that the reason why this conference worked so well was because as junior scholars, we fashioned the conference to be just what we needed. Although we do not want to advocate for more junior scholars to take on the daunting task of planning a mentoring conference, the observation does offer a good insight: the particular needs and concerns of junior scholars need to be strongly considered when planning a mentoring conference. For example, when we plan a second iteration of the conference in several years, we will convene a planning committee of junior and senior scholars across fields to work together to tailor the program to existing needs.

Our conference can serve as a basic model for future mentoring conferences in the discipline and across interdisciplinary areas in the social sciences. The model can be tweaked in any number of ways to best meet the needs of its participants. We are confident that these methods can be transferred into other areas to plan similar conferences or even to improve professional development and mentoring opportu-

\section{The particular needs and concerns of junior scholars need to be strongly considered when planning a mentoring conference.}

Participant reactions were less positive on our attempt to connect campaign professionals and academics through the cosponsored panel with practitioners. Fifteen percent of respondents felt we did not meet this goal. Our moderators, Debbie Walsh and Kelly Dittmar from the Center for American Women and Politics, performed admirably in asking insightful questions. However, this was the only panel in the conference where we followed the "traditional" model of presenters with an audience. Had we structured this interaction differently-that is, with smaller groups or more advance preparation-conference participants may have found more concrete links between theory and practice.

In terms of conference structure, $30 \%$ agreed the conference should have been less structured. Several commented that one thing to improve on was to give "more free time at the end of the day" and that it was "a lot to fit into two days" and could be "spread out over three days." Similarly, one participant asked for a "later start time." One good suggestion was to have a break before a later dinner. We realize that the days were long and action-packed: participants met in the hotel lobby at 7:30 a.m. for transportation to the conference location and did not return until 8:00 or 9:00 p.m. ${ }^{3}$ However, this schedule may have been one of the things that made the conference work. Had the conference lasted longer, we might not have been able to attract high-profile senior scholars to attend; moreover, participants may have nities within existing disciplinary organizations, organization sections, or academic institutions. For example, one senior scholar participant, who serves as a dean at her institution, plans to try some of the techniques for junior faculty development. In addition, the panels sponsored by APSA sections could be another effective place to consider adjustments geared toward mentoring.

The positive response from participants was truly overwhelming. Many participants noted that the conference had profoundly influenced them, stating things such as, "This is by far the best conference ever, in terms of both information and fun, and more fun than most weekends I've had in years," "Best conference I've attended! Most productive," "The conference was helpful, motivating, interesting, and inspiring," and "This has been amazing and I feel it will have huge positive benefits on my life and career for many years to come." Finally, in the margins next to the question about whether we met our goal to address the leaky pipeline, one participant wrote that the conference "may have saved me from leaking out of the pipeline."

As junior scholars in women and politics, we both had transformative experiences at the conference. We feel we have found our academic home, a group of junior and senior scholars on whom we will continue to lean and from whom we expect to find support throughout our careers. And, importantly, we feel confident that, along with our junior 
scholar participant counterparts, we will not leak out of the pipeline.

\section{ACKNOWLEDGMENTS}

We thank the National Science Foundation (\#SES-1014854), Brian Humes, Miami University Department of Political Science, Miami University College of Arts and Science, the College of Wooster, Simon and Schuster, all the participants at the 2011 "New Research on Gender in Political Psychology" conference, Alan Abes, Erin Cassese, Leonie Huddy, David Redlawsk, Kira Sanbonmatsu, Bas van Doorn, Debbie Walsh, Natalie McCoy, and especially Space 2 Burn for logo, website, and design of all conference materials and Abbey Smanik for assistance.

\section{NOTES}

1. Additional information about the conference can be found at http:// genderandpolipsych.com/

2. The APSA Teaching and Learning "Track" model also has great potential for establishing meaningful relationships among scholars.

3. The full conference schedule is available at http://genderandpolipsych. $\mathrm{com} /$.

\section{REFERENCES}

American Political Science Association. 2005. Women's Advancement in Political Science: A Report of the APSA Workshop on the Advancement of Women in Academic Political Science in the United States. Washington, DC: American Political Science Association.
American Political Science Association. 2011. Political Science in the 21st Century: Report of the Task Force on Political Science in the 21st Century. Washington, DC: American Political Science Association.

Kelly, Rita Mae, Linda M. Williams, and Kimberly Fisher. 1994. "Women \& Politics: An Assessment of Its Role within the Discipline of Political Science." Women and Politics 14 (4): 3-18.

Sorcinelli, Mary Deane, and J.H. Yun. 2007. "From Mentors to Mentoring Networks: Mentoring in the New Academy," Change Magazine 39 (6): 58

Traister, Rebecca. 2010. Big Girls Don't Cry: The Election That Changed Everything for American Women. New York: Free Press.

Van Emmerick, I. 2004. "The More You Can Get the Better: Mentoring Constellations and Intrinsic Career Success." Career Development International $1(6 / 7): 578$

Yun, J.H., and Mary Deane Sorcinelli. 2008. "When Mentoring Is the Medium: Lessons Learned from Mutual Mentoring as a Faculty Development Initiative." To Improve the Academy 27: 365-84.

\section{CONTRIBUTORS}

Angela L. Bos is an assistant professor in the department of political science at the College of Wooster. She can be reached at abos@wooster.edu.

Erin C. Cassese (Erin.Cassese@mail.wvu.edu) is an assistant professor of political science at West Virginia University.

Lauren E. Duncan is a professor of psychology at Smith College. She can be reached at lduncan@email.smith.edu.

Jill S. Greenlee is an assistant professor of political science at Brandeis University and can be reached at greenlee@brandeis.edu.

Rebecca J. Hannagan is assistant professor of political science at Northern Illinois University and can be reached at rhannaga@niu.edu.

Monica C. Schneider is an assistant professor in the department of political science at Miami University, Ohio. She can be reached at MSchneider@muohio.edu. 


\section{APPENDIX}

\section{Bingo Icebreaker}

Participants were asked to mingle with one other to obtain signatures of other participants who have done various things. We used a free online Bingo card creator to generate the cards. The items tied in with the conference's intellectual themes (e.g., someone who has "reviewed a gender paper in the past 3 months" or "has read an article outside their home discipline in the past month"), mentoring, and professional development themes (e.g., "has a difficult time balancing family and career" or "has published a book"), and nonacademic topics (e.g., "has more than two televisions in their home").

\section{Full Bingo Item List:}

- Has read US Weekly in the past 3 months

- Flight/train was delayed more than 30 minutes

- Read an article outside their disciplinary home in the last month

- Home discipline is political science

- Home discipline is psychology

- Read all of the conference papers

- Believes Sarah Palin will run in 2012

- Teaches at a college/university smaller than 7,000

- Got their PhD in the last 3 years

- Has published a book

- Has edited a volume

- Is going to Istanbul for ISPP

- Teaches a women and politics class

- Has ever finished prepping for class less than 1 hour before class started

- Plans to attend the MPSA reunion dinner

- Has a difficult time balancing family and career

- Believes gender affects the class dynamic

- Has had/adopted a baby pretenure

- Has ever skipped watching a State of the Union Address

- Is friends with students on Facebook

- Uses undergraduate research assistants

- Uses graduate students as research assistants

- Has conducted an experiment

- Has published on gender using NES data

- Doesn't get paid over the summer but works anyway

- Uses a Mac

- Uses SPSS as their statistical software of choice

- Prefers to coauthor

- Is visiting New Brunswick for the first time

- Wants to organize the next conference

- Has reviewed a paper on gender in the last 3 months

- Has/had a good mentor in their department at their current institution

- Has ever burned a review

- Has ever had a review they'd be embarrassed to share

- Considers The Daily Show news

- Gave an exam last week

- Has ever been department chair

- Has more than two TVs in their home

- Has ever seen Sarah Palin's reality TV show

- Went to an Obama/McCain rally in the 2008 election

- Has ever run for elective office (or plans to)

\section{Mentoring Group Discussion Starters}

The mentoring group "discussion starters" for each conference meal were printed separately on card stock and assembled into one deck of cards for each mentoring group. The questions are listed below. Each mentoring group had one senior scholar who served as 
facilitator. At each meal, the facilitator relied on the cards to guide the group's discussion. The mentoring groups were named after famous political women such as Madeleine Albright.

\section{\#1: Introductions}

Each participant introduces themselves, answering the following questions:

-What is your name, title, and current institution?

- How would you describe the relative balance of teaching and research in your job?

- What are your main research interests?

- What do you like most and least about your job?

\section{\#2: Research}

- How can we deal with and overcome rejection in the academy?

- How can we "sell" gender, psychological, and experimental work to mainstream journals?

- How can we choose the best journal?

- How do we understand the relative value of different kinds of publications-like edited volume pieces vs. journal articles, vs. books, etc.?

\section{\#3: Teaching}

- What classes do you teach? What size/s are they?

- How do gender and age affect the dynamics of our classrooms?

- How can we successfully engage students in productive discussions about gender issues?

- What are some successful activities or projects you've used related to gender? Political psychology?

\section{\#4: Managing All the "Extras"}

- Related to service: how can we be good colleagues/citizen-scholars without going crazy?

- What are some examples of service you *should* do versus should not?

- How do we negotiate research leave and family leave?

- How can we balance-or juggle-work and family?

- How can we get the most out of conferences?

\section{\#5: Conference Wrap Up}

- Based on your conference experience, what concrete actions will you take to improve your research and teaching?

- How will you specifically continue to support the colleagues you have met at this conference?

- Of the various sessions, are there specific ones that you would be interested writing about our discussions for possible publication?

\section{Prompts for Journal Writing}

- Often we will hear people say, “It's too late in this semester to make any major changes." But, it's not too late! Write about two to three specific and feasible changes that you can make this semester to help you balance work and your personal life and be more productive.

- Name three people who you think you could send your research and writing to. Name the specific paper on which you might like feedback and a reasonable date that you could send this paper.

- Write about two new research ideas that you had as a result of the discussion in the conference. Bonus points if you generate a rough schedule of getting this research accomplished.

- Write about two new teaching ideas that you had as a result of the discussion in the conference. Bonus points if you write specifically about how you hope to incorporate these ideas into your classes this semester or next.

- If you presented your paper (or if you have a paper in the pipeline right now), write about the specific things that need to be done to send this paper to publication, two to three potential publication outlets, and a reasonable date that you could send out this paper.

- Do you think that there are specific themes in the conference that would warrant a collective publication effort? Describe these and how we might accomplish this task.

- For junior scholars, what were the three most important things you learned about getting tenure?

- For senior scholars, what was the most rewarding aspect of this conference for you? Do you think you can fit mentoring junior scholars in with your other duties? How can you make sure that your institution rewards you for doing so?

- In one month, many of us will reconvene at the Midwest Political Science Association meeting for dinner and a roundtable. What progress will you make on your research by that meeting? Upon reflecting on the conference, what would you most like to discuss at the roundtable?

(continued) 


\section{Conference Evaluation Items}

Note: All items were measured on a 5-point, fully labeled scale from $1=$ "strongly disagree" to $5=$ "strongly agree." Note that some of the closed-ended questions were worded negatively to avoid "yea-saying."

\section{Conference Goals}

1. The conference met its goal to bring together junior and senior scholars in mentoring.

2. The conference did not meet its goal to facilitate publication of gender and political psychology research in top research outlets.

3. The conference met its goal to connect academics studying gender and political psychology with campaign professionals.

4. The conference failed to encourage participants to consider meeting the challenges to teaching gender.

5. I don't see how this type of conference can help fix the "leaky pipeline."

\section{Your Experience \& Conference Logistics}

6. This conference was more helpful than other conferences in helping me achieve my professional goals.

7. My mentoring group discussions proved unhelpful to me.

8. This conference provided important professional development experiences that are not available to me at my current institution.

9. The logistics of the conference ran smoothly.

10. I felt that the conference coordinators could have improved the preconference communication.

11. The conference should have had less structure.

\section{Looking Ahead}

12. I do not plan to keep in touch with other conference participants.

13. I did not gain any concrete ideas regarding teaching gender.

14. I would participate in a mentoring conference like this in the future.

15. I will not collaborate with any fellow participants in the future.

16. I met other scholars to whom I could send my research to in the future for suggestions.

17. For junior scholars only: The conference helped demystify the tenure process.

18. For junior scholars only: I feel more confident in my ability to navigate the world of academic publishing as a result of this conference.

19. For senior scholars only: I feel like I had a positive impact on the career of a junior scholar.

\section{Open-Ended Sharing}

20. Which two to three aspects of the conference were most helpful to you in meeting your professional goals?

21. If there were to be another mentoring conference such as this, what one or two things would you want to see changed?

22. Other Comments? 